
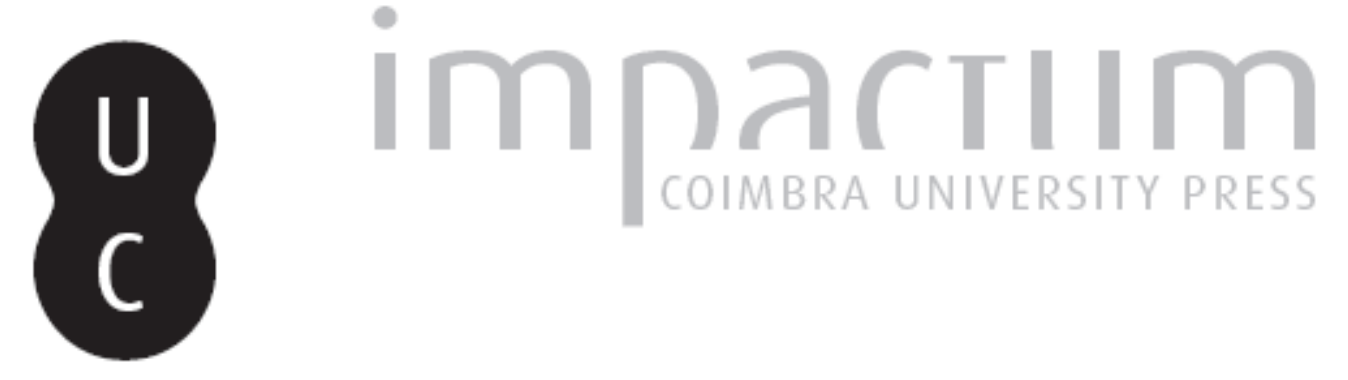

\title{
Time preference and cyclical endogenous growth in an AK growth model
}

\section{Autor(es): Gomes, Orlando}

Publicado por: Faculdade de Economia da Universidade de Coimbra

URL persistente:

URI:http://hdl.handle.net/10316.2/25246

DOI:

DOI:http://dx.doi.org/10.14195/2183-203X_28_2

Accessed : $\quad$ 26-Apr-2023 08:19:46

A navegação consulta e descarregamento dos títulos inseridos nas Bibliotecas Digitais UC Digitalis, UC Pombalina e UC Impactum, pressupõem a aceitação plena e sem reservas dos Termos e Condições de Uso destas Bibliotecas Digitais, disponíveis em https://digitalis.uc.pt/pt-pt/termos.

Conforme exposto nos referidos Termos e Condições de Uso, o descarregamento de títulos de acesso restrito requer uma licença válida de autorização devendo o utilizador aceder ao(s) documento(s) a partir de um endereço de IP da instituição detentora da supramencionada licença.

Ao utilizador é apenas permitido o descarregamento para uso pessoal, pelo que o emprego do(s) título(s) descarregado(s) para outro fim, designadamente comercial, carece de autorização do respetivo autor ou editor da obra.

Na medida em que todas as obras da UC Digitalis se encontram protegidas pelo Código do Direito de Autor e Direitos Conexos e demais legislação aplicável, toda a cópia, parcial ou total, deste documento, nos casos em que é legalmente admitida, deverá conter ou fazer-se acompanhar por este aviso.

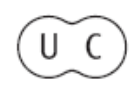




\section{N $\odot$ T $A E G \odot N O M I C A S$}

\section{ARGENTINO PESSOA MULTINATIONAL CORPORATIONS, FOREIGN INVESTMENT, AND ROYALTIES AND LICENSE FEES: EFFECTS ON HOST-COUNTRY TOTAL FACTOR PRODUCTIVITY}

ORLANDO GOMES TIME PREFERENCE AND CYCLICAL ENDOGENOUS GROWTH IN AN AK GROWTH MODEL

\section{$-3$}

$\rightarrow$

c.

6

3

$\theta$

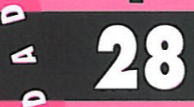

-

$\omega$

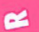

w

$\Rightarrow$

-

$z$

E

$a$

a

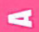

-

EF

$\odot$

$z$

$\odot$

v

w

w

a

w

0

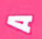

0

$\sim$

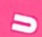

ن 
Time Preference and Cyclical Endogenous Growth in an AK Growth Model

Orlando Gomes* Escola Superior de Comunicą̧ão Social, IPL; UNIDE/ISCTE - ERC

$O$ artigo desenvolve um modelo de crescimento endógeno tipo AK com uma taxa de preferência intertemporal endogenamente determinada. Seguindo a literatura relacionada com este tema, assume-se que o grau de impaciência revelado pelo agente representativo, no que respeita ao consumo futuro, depende do rendimento. Para ser preciso, o modelo proposto estabelece uma relação entre o hiato do produto e a taxa de desconto associada à sequência futura de funções de utilidade. São analisadas quer a dinâmica local quer a dinâmica global. Do ponto de vista da análise local, vários resultados de estabilidade podem ser obtidos, dependendo dos valores de parâmetros. $O$ estudo de dinâmica global permite encontrar ciclos económicos endógenos na circunstância em que o agente representativo falha na consideração de um requisito fundamental de optimalidade. Numa segunda etapa, o modelo é alargado ao papel do lazer e, neste caso, as flutuações endógenas já serão compatíveis com um cenário de completa racionalidade.

\footnotetext{
* I would like to acknowledge the important comments of an anonymous referee, which helped to substantially improve the contents of the paper. I am also grateful to Luís Cavique for helpful assistance. The usual disclaimer applies.
}

Cet article développe un modèle de croissance endogène de type $A K$ avec un certain niveau de préférence intertemporelle déterminée endogènement. Dans la littérature se rapportant à cette question, en ce qui concerne la consommation future, il est supposé que le degré d'impatience manifesté par l'agent représentatif dépend du revenu. Pour être précis, le modèle propose d'établir une relation entre l'intervalle du produit et le taux d'escompte associés à la séquence future de fonctions d'utilité. Sont analysées à la fois et la dynamique locale et la dynamique globale. Du point de vue de l'analyse locale, plusieurs résultats de la stabilité peuvent être atteints, selon les valeurs des paramètres. L'étude de la dynamique globale permet de trouver des cycles économiques endogènes, quand l'agent représentatif rate une exigence fondamentale de l'optimalité. Dans une deuxième étape, le modèle comprendra aussi le rôle des loisirs et, dans ce cas, les fluctuations endogènes sont déjà compatibles avec un scénario complet de la rationalité.

The paper develops an AK endogenous growth model with an endogenously determined rate of intertemporal preference. Following some of the related literature, we assume that the degree of impatience that is revealed by the representative agent, regarding future consumption, depends on income. To be precise, the proposed framework establishes a link between the output gap and the discount rate attached to the sequence of future utility functions. We analyze both local and global dynamics. From a local analysis point of view, a variety of stability results is possible to obtain, depending on parameter values. The study of global dynamics allows finding endogenous business cycles in the circumstance in which the representative agent overlooks one essential requirement for optimality. On a second stage, the model is extended to include the role of leisure and, in this case, endogenous fluctuations are compatible with full rationality.

Classificação JEL: O41, C61, E32. 
1. Introduction

The paper studies the implications of assuming an endogenous rate of time preference when assessing the dynamics of a simple AK endogenous growth model. The proposed setup is developed in discrete time and takes, as the central assumption, the dependence of the utility discount rate on the economy's output gap. We consider that a representative agent chooses her rate of time preference by evaluating how the economy performs relatively to a potential output time trend. Typically, one should expect a low discount rate when the economy performs well (the representative agent becomes more patient) and a high discount rate when the economic performance falls short of its potential (impatience rises).

The model has its inspiration in earlier studies concerning endogenous time preference and growth, in the tradition of Uzawa (1968) and Epstein (1987). Three features distinguish our model from other approaches. First, we focus solely on endogenous growth, i.e., relevant variables (output, capital and consumption) will grow at a same constant rate in the long term (see Dolmas, 1996, Drugeon, 1996, and Palivos et al., 1997 for alternative approaches to the endogenous growth - endogenous time preference analysis).

Second, we concentrate solely on the role of output as an influence over the way the future is discounted. Typically, consumption is the central variable, i.e., the discount rate is influenced by the level of consumption; this relation tends to have a positive sign, that is, individuals tend to become increasingly impatient (higher discount rate) with a rise in the present level of consumption. Here, we neglect consumption and take income as the single determinant of the discount rate. In this respect, we follow relevant empirical work by Hausman (1979),

Lawrance (1991) and Samwick (1998), who study the relation between utility discounting and income levels; they unanimously agree that the evidence strongly points to a rate of time preference that varies inversely with the agent's income. Building on this evidence, Becker and Mulligan (1997) develop a model where the positive relation between wealth and patience is explored.

Third, we are not directly concerned with the level of income, but with a relative measure: we consider that the discount rate is a function of the output gap. Thus, our focus is not on the statement 'the wealthier are more patient' but with the idea that 'if my present level of wealth is above the expected / potential level, then I am more patient'. This seems a reasonable perspective, in the sense that the representative agent reacts to business cycles and formulates a subjective appreciation of the value of future consumption on the grounds of a more or less optimistic view of the future, which is given by a comparison between effective and potential output. Therefore, a two step procedure is adopted: first, the agent evaluates how the economy performs and this has impact over her sentiment or confidence to the future; second, optimistic sentiment tends to be translated on a more patient attitude towards consumption, while a pessimistic sentiment will lead to a more pronounced impatience. All things considered, we might say that our assumption is basically that patience is procyclical.

The idea that patience is procyclical is also present in Meng (2006), who develops a model of a socially determined discount rate. Under his analysis, indeterminacy is found when, in a single agent intertemporal utility maximization problem, the agent becomes more willing to defer consumption as a result of an increasingly wealthier economy. The indeterminacy result arises if along with the previous living standard - patience relation, it is also established a positive relation between the value of the discount rate and the economy wide level of consumption. Besides the indeterminacy result, the referred relations also allow to measure how lifetime utility is influenced by society. If one takes as reasonable the idea that individual patience rises with aggregate income and falls with aggregate consumption, then it is straightforward to perceive that the agent's lifetime utility rises when the economy becomes wealthier and falls when average consumption rises. In the words of Meng (2006), 
"the two conditions imply that the society's living standard is like a public good that yields a positive externality to the agent's utility, and the society's consumption is like a public good that delivers a negative externality" (page 2677).

The effect produced by social consumption can be thought as a jealousy effect. Individuals become eager to consume when the economy's levels of consumption rise.

In the following sections, we concentrate on the role of output fluctuations over time preference and of time preference over long term growth. Consumption effects are overlooked, and there is a coincidence between individual and social income effects, since we are working with a single representative agent. We will consider a generic relation between the output gap and the discount rate, in the sense that we leave open the possibility of positive output gaps producing a positive or a negative effect over such rate. Nevertheless, we will find that interesting dynamic results arise eminently on the reasonable circumstance where the discount rate is countercyclical (i.e., patience is procyclical).

The undertaken analysis is both local and global. On a local perspective, we find that instability tends to persist for most of the admissible parameter values, although saddle-path stability can prevail as well. Local indeterminacy or fixed-point stability (the case in which the two eigenvalues of the Jacobian matrix of the system are inside the unit circle) is absent under the selected parameterization.

From a global dynamics viewpoint, we discover an interesting endogenous business cycles result, which occurs in the presence of the relation of opposite sign between the output gap and the discount rate. At this level, we might argue that the endogenous time preference version of the standard growth model becomes one additional framework of growth in which endogenous fluctuations are likely to arise, as it happens on other growth analyses, namely the ones that consider increasing returns / externalities on production (e.g., Christiano and Harrison, 1999 and Guo and Lansing, 2002), learning (Cellarier, 2006), financial development (Caballé et al., 2006) or competitive environments under extreme conditions regarding the shape of the production function or the constant value of the intertemporal discount rate (e.g., Nishimura et al., 1994, Nishimura and Yano, 1995 and Boldrin et al., 2001).

The relation between time preference and cyclical motion is explored in the literature by Balasko and Ghiglino (1995) and Drugeon (1998). The first authors study the presence of endogenous business cycles on an overlapping generations model. Conventionally, this type of model generates cycles if unrealistically high rates of time preference are assumed. The argument of the authors is that if preferences are not homothetic, it is possible to prove that endogenous fluctuations arise under reasonable levels of impatience. Drugeon (1998), in turn, assumes an endogenous rate of time preference, which depends on the individual level of consumption (negatively) and on the consumption standards of the society as a whole (positively). Combining endogenous impatience with the idea that higher consumption standards of the society imply a greater productivity of its members, Drugeon finds conditions for local indeterminacies and sustained oscillation motion, without the need of assuming increasing returns or any unconventional form for the production function.

The result on endogenous cyclical motion requires a limitation on the capacity of the representative agent to act in a fully optimal way. In particular, one has to assume that the agent is unable to avoid a negative steady state growth rate (consumption and capital fall at a constant rate approaching zero asymptotically). This bounded rationality scenario is the straightforward outcome of the inability of the representative agent to take, alongside with other optimality conditions, a transversality condition able of ruling out undesirable long term results.

On a second stage, we extend the proposed model by considering that the representative agent attributes utility to leisure. Assuming decreasing marginal utility concerning the leisure argument, alongside with decreasing marginal utility of consumption, one encounters an extended version of the benchmark model, where cycles persist for positive leisure utility, although as one increases the relative relevance of leisure the amplitude of the cycles becomes less pronounced. 
This extension is relevant because it allows to find cyclical motion in a fully optimal scenario, i.e., when the transversality condition is met and thus long term growth is strictly non negative.

The remainder of the paper is organized as follows. Section 2 describes the model's features. Sections 3 and 4 are dedicated to the study of local and global dynamics. In section 5, we introduce leisure in the utility function and study the dynamic properties of this version of the model. Finally, section 6 concludes.

\section{The AK Growth Model with Time Preference Depending on the Output Gap}

Consider a standard endogenous growth economy. Variables $y_{t}, k_{t}$ and $c_{t}$ respect to effective output or income, stock of capital and level of consumption in moment $t$. These variables may be understood as aggregate levels or per capita values, because no population growth is assumed. The capital accumulation constraint has its habitual form, $k_{t+1}=y_{t}-c_{t}+(1-\delta) \cdot k_{t}, k_{0}$ given, with $\delta \geq 0$ the depreciation rate. The representative household maximizes consumption utility over time under an infinite horizon, i.e., she maximizes $V_{0}=\sum_{t=0}^{+\infty}\left(\beta_{t}\right)^{t} \cdot U\left(c_{t}\right)$. Function $U$ is a conventional continuous, positive and concave utility function and $\beta_{t}<1$ is the discount factor. Concerning utility, we just assume a simple logarithmic function, $U\left(c_{t}\right)=\ln c_{t}$, and the production process in our endogenous growth framework is just given by an AK function, $y_{t}=A k_{t}$, with $A>0$ the index of technology.

The single difference between the standard AK model and our framework is that we let the discount factor vary as a function of the economy's output gap, $x_{t}$. The output gap is defined as the difference in logs between effective output, $y_{t}$, and potential output, $y_{t}{ }^{*}$. This last notion of output coincides with a long run trend, that is, $y_{t}^{*}$ is the steady state value of $y_{t}$, and therefore the steady state must be characterized by a null output gap, $x^{*}=0$.

Let $\rho>0$ be the discount rate in the absence of deviations of the output relatively to its potential level and consider the following discount factor: $\beta\left(x_{t}\right)=1 /\left[1+\rho \cdot\left(1+f\left(x_{t}\right)\right)\right]$, with $f\left(x_{t}\right)=a \cdot x_{t}$ and $a$ a parameter representing the extent in which the output gap influences the rate of time preference. According to the discussion in the introduction, we might expect $a$ to be negative, i.e., there is, eventually, a relation of opposite sign between the output gap and the discount rate, meaning that the better is the performance of the economy relatively to its potential, the less the representative consumer discounts future utility, that is, the more patient the agent will be. To study the model's dynamics, we do not impose a priori any constraint on the value of this parameter.

An additional assumption is that the representative agent takes decisions today concerning the discount of future utility based on the available information about the output gap, which we consider to be the information of the last period, i.e., $\beta_{t}=\beta\left(x_{t-1}\right)$. With the previous problem's specification we may compute, on a straightforward manner, a two endogenous variables - two equations system able to characterize the movement over time of the aggregates capital and consumption. This system is obtained by building a Hamiltonian function and, from this, by computing the first order conditions,

$H\left(k_{t}, c_{t}, q_{t}\right)=U\left(c_{t}\right)+q_{t+1} \cdot\left[(A-\delta) \cdot k_{t}-c_{t}\right]$

In equation (1), $q_{t}$ is the present-value co-state variable of $k_{t}$. We may define $q_{t} \equiv \beta\left(x_{t-1}\right) \cdot p_{t}$ the current-value co-state variable of $k_{t}$. Determining the first order conditions, one gets,

$H_{c}=0 \Longrightarrow \beta\left(x_{t}\right) \cdot p_{t+1}=c_{t}^{-1}$

$$
\beta\left(x_{t}\right) \cdot p_{t+1}-p_{t}=-H_{k} \Longrightarrow
$$

$(1+A-\delta) \cdot \beta\left(x_{t}\right) \cdot p_{t+1}+\beta_{k} \cdot p_{t+1} \cdot\left[(A-\delta) \cdot k_{t}-c_{t}\right]=p_{t}$

with $\beta_{k}=-\rho \cdot a \cdot\left(\beta\left(x_{t}\right)\right)^{2} / k_{t}$ the derivative of the discount factor in order to $k_{t}$. 
Resorting to relation (2), one may transform (3) into an equation of motion that characterizes the evolution of consumption over time, i.e.,

$c_{t+1}=\frac{1+A-\delta-\rho \cdot a \cdot(\mathrm{A}-\delta) \cdot \beta\left(x_{t+1}\right)}{1 /\left(\beta\left(x_{t}\right) \cdot c_{t}\right)-\rho \cdot a \cdot \beta\left(x_{t+1}\right) / k_{t+1}}$

Equation (4) is derived in appendix A.

Let parameter $\gamma$ represent the long term growth rate of the various endogenous variables (from the production function, the resource constraint and difference equation (4), it is straightforward to perceive that output, capital and consumption all grow at a same steady state growth rate). It will be useful to work with variables that do not grow in the long term, and thus we define $\hat{y}_{t} \equiv \frac{y_{t}}{(1+\gamma)^{t}}, \hat{k}_{t} \equiv \frac{k_{t}}{(1+\gamma)^{t}}$, and $\hat{c}_{t} \equiv \frac{c_{t}}{(1+\gamma)^{t}}$; note that $\hat{y}^{*} \equiv \frac{y_{t}^{*}}{(1+\gamma)^{t}}$, is a constant. The dynamic system we propose to analyze is composed by the capital accumulation constraint and the consumption equation in (4), after replacing the original variables by the constant steady state variables,

$\hat{k}_{t+1}=\frac{1+A-\delta}{1+\gamma} \cdot \hat{k}_{t}-\frac{1}{1+\gamma}, \cdot \hat{c}_{t}$

$\hat{c}_{t+1}=\frac{1}{1+\gamma} \cdot \frac{1+A-\delta-\rho \cdot a(A-\delta) \cdot \beta\left(\hat{x}_{t+1}\right)}{1 /\left(\beta\left(\hat{x}_{t}\right) \cdot \hat{c}_{t}\right)-\rho \cdot a \cdot \beta\left(\hat{x}_{t+1}\right) /\left((1+A-\delta) \cdot \hat{k}_{t}-\hat{c}_{t}\right)}$

Note that $\beta\left(\hat{x}_{t}\right)=1 /\left[1+\rho \cdot\left(1+a \cdot\left(\ln \hat{y}_{t}-\ln \hat{y}_{t}^{*}\right)\right)\right]$, which is equivalent to $\beta\left(\hat{x}_{t}\right)=1 /\left[1+\rho \cdot\left(1+a \cdot\left(\ln \hat{k}_{t}-\ln \hat{k}^{*}\right)\right)\right]$, with $\hat{k}^{*}$ the steady state value of $\hat{k}_{t}$.

The computation of steady state conditions from (5) and (6), allows finding a unique and constant consumption-capital ratio and to determine a unique rate of growth for the main economic aggregates. By solving $\left(\hat{k}_{t+1}, \hat{c}_{t+1}\right)=\left(\hat{k}_{t}, \hat{c}_{t}\right) \equiv\left(\hat{k}^{*}, \hat{c}^{*}\right)$ we obtain the ratio $\hat{c}^{*} / \hat{k}^{*}=A-\delta-\gamma$, with the growth rate given by $\gamma=\frac{1+A+\delta-1 / \beta}{1 / \beta+(1-\beta) \cdot a}$ [note that we define $\left.\beta \equiv 1 /(1+\rho)\right]$. This is the growth rate of effective output, capital and consumption in the long run and of the potential values of the variables regardless from the assumed time moment. Proposition 1 refers to the growth rate result.

Proposition 1. In the endogenous growth model with endogenous time preference, the following conditions characterize long term economic growth:

(i) if $1+A-\delta>1 / \beta$ and $a<-1 /(\beta \cdot(1-\beta))$, then the economy's steady state growth rate is negative and it declines with an increase in impatience;

(ii) if $1+A-\delta>1 / \beta$ and $a>-1 /(\beta \cdot(1-\beta))$, then the economy's steady state growth rate is positive and it declines with an increase in impatience;

(iii) if $1+A-\delta<1 / \beta$ and $a<-1 /(\beta \cdot(1-\beta)$ ), then the economy's steady state growth rate is positive and its value rises with an increase in impatience;

(iv) finally, if $1+A-\delta<1 / \beta$ and $a>-1 /(\beta \cdot(1-\beta))$, then the economy's steady state growth rate is negative and its value rises with an increase in impatience.

Proof: It is straightforward to separate four cases, regarding the sign of $\gamma$. In cases $1+A-\delta>1 / \beta \wedge a>-1 /(\beta \cdot(1-\beta))$ and $1+A-\delta<1 / \beta \wedge a<-1 /(\beta \cdot(1-\beta))$, the growth rate is positive; when $1+A-\delta>1 / \beta \wedge a<-1 /(\beta \cdot(1-\beta))$ or $1+A-\delta<1 / \beta \wedge a>-1 /(\beta \cdot(1-\beta))$, the growth rate is negative. Obviously, $1+A-\delta=1 / \beta$ implies $\gamma=0$, while $a=-1 /(\beta \cdot(1-\beta))$ 
corresponds to an infinite growth rate. Moreover, computing the derivative $\frac{\partial \gamma}{\partial a}=-(1-\beta) \cdot \frac{1+A-\delta-1 / \beta}{[1 / \beta+(1-\beta) \cdot a]^{2}}$ we find a negative value for the derivative if $1+A-\delta>1 / \beta$ and

a positive value when $1+A-\delta<1 / \beta$. Thus, when the first one of these relations holds, $\gamma$ falls with increases in $a$; since $a$ is a measure of impatience (a higher $a$ means that for a same output gap, the representative agent increases her degree of impatience by rising the time preference rate), it is true that the referred condition implies a relation of the same sign between growth and patience. If the second relation holds, $\gamma$ and $a$ evolve in the same direction, that is, less patience or a higher discount rate are in this case synonymous of an increasing growth rate.

Note that under condition $a=0$, we are back on the trivial AK model, where $\gamma=\beta \cdot(1+A-\delta)-1$. Note, as well, that possibilities (i) and (iv) of proposition 1 are ruled out once we add to the optimality conditions a transversality condition $\lim _{t \rightarrow+\infty} k_{t} \cdot \beta\left(x_{t-1}\right)^{t} \cdot p_{t}=0$, or, equivalently,

$\lim _{t \rightarrow+\infty} \frac{k_{t}}{c_{t-1}} \cdot \beta\left(x_{t-1}\right)^{t}=0$. This makes sense as a terminal condition if capital and consumption

grow in time at a same positive (or zero) rate. Its purpose is, in fact, to drive away the possibility of undesirable or senseless long term outcomes. Because the inability of the representative agent in taking into account the transversality condition (and therefore the possibility of negative growth rates) is a basic requisite for the persistence of business cycles in this environment, as one will realize in section 4 , we maintain this as an open possibility: the failure to be fully rational and to optimize accordingly implies a disaccumulation of capital and a loss of consumption that occur under a pattern of irregular cycles rather than linearly. Endogenous volatility and limited rationality arise, in this way, as the two faces of a same coin.

One may argue that even a boundedly rational agent is capable of perceiving that the chosen growth path will lead to an everlasting decline on consumption and capital levels and, therefore, that the agent should be able to select an alternative growth path. Although having this in mind, we will keep this possibility in the analysis that follows, since it constitutes a first step to build the analysis in section 5, where the introduction of leisure in the utility function allows encountering cyclical motion for positive growth rates obtained under a strict optimality behaviour.

Let us return to the basic dynamic properties of the system in consideration.

Replacing the expression of the growth rate in the consumption - capital ratio one obtains $\frac{c^{\wedge *}}{\hat{k}^{*}}=(1-\beta) \cdot \frac{a \cdot(A-\delta)+(1+A-\delta) / \beta}{(1 / \beta+(1-\beta) \cdot a}$. Thus, the following result holds,

Proposition 2. In the endogenous growth model with endogenous time preference:

(i) if $1+A-\delta>1 / \beta$, then the steady-state consumption - capital ratio rises with an increase in impatience;

(ii) if $1+A-\delta<1 / \beta$, then the steady-state consumption - capital ratio falls with an increase in impatience.

Proof: Just compute $\frac{\partial\left(\hat{c}^{*} / \hat{k}^{*}\right)}{\partial a}=\frac{(1-\beta) \cdot \gamma}{1 / \beta+(1-\beta) \cdot a}$. This is a positive value under $1+A-\delta>1 / \beta$

and a negative value in the opposite circumstance, that is, $1+A-\delta<1 / \beta$, independently of the sign of $a$. Thus, when the first of the conditions holds, the ratio $\hat{c}^{*} / \hat{k}^{*}$ and $a$ move in the same direction, that is, an increasing impatience translated on a higher discount rate (higher $a$ ) is synonymous of a higher relative level of consumption in the long term. Symmetrically, the second condition implies a movement of opposite direction, that is, increased patience (lower $a$ ) leads to a lower relative level of consumption in the long term

The result in proposition 2 should be carefully evaluated. For instance, assuming that $1+A-\delta>1 / \beta$, we can have a higher relative level of consumption as the representative consumer becomes increasingly impatient, but nevertheless the absolute level of consumption can be in fact lower as 
the discounting becomes stronger. This is clear if we look at the result in proposition 1 . In the considered case, the economy grows less as the impatience rises; thus, we may have a rise in $\hat{c}^{*} / \hat{k}^{*}$, but with a decline in the growth rate of both aggregates. Therefore, impatience favours consumption relatively to capital accumulation in the long term but penalizes both, as the economy becomes less capable of growing.

\section{Local Dynamic Behaviour}

The linearization of system (6)-(7) around $\left(\hat{k}^{*}, \hat{c}^{*}\right)$ yields,

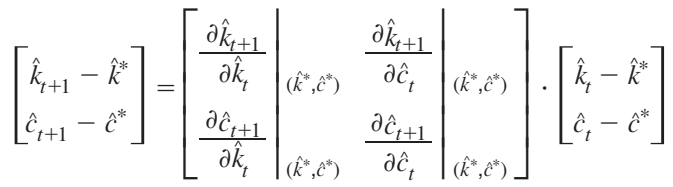

The elements of the Jacobian matrix are

$$
\begin{aligned}
& \left.\frac{\partial \hat{k}_{t+1}}{\partial \hat{k}_{t}}\right|_{\left(\hat{k}^{*}, \hat{c}^{*}\right)}=\frac{1+A-\delta}{1+\gamma} ; \\
& \left.\frac{\partial \hat{k}_{t+1}}{\partial \hat{c}_{t}}\right|_{\left(\hat{k}^{*}, \hat{c}^{*}\right)}=-\frac{1}{1+\gamma} ; \\
& \left.\frac{\partial \hat{c}_{t+1}}{\partial \hat{k}_{t}}\right|_{\left(\hat{k}^{*}, \hat{c}^{*}\right)}=\frac{A-\delta-\gamma}{(1+\gamma) \cdot[1+A-\delta-(1-\beta) \cdot a \cdot(A-\delta)]} \cdot \\
& \left.\right|_{\left.(1-\beta)^{2} \cdot a^{2}-(1+\mathrm{A}-\delta) \cdot \gamma-\frac{1-\beta}{\beta} \cdot a \cdot(1+\gamma)^{2}-(1-\beta) \cdot a \cdot(1+A-\delta) \cdot(\mathrm{A}-\delta-y)\right]} \\
& \left.\frac{\partial \hat{c}_{t+1}}{\partial \hat{c}_{t}}\right|_{\left(\hat{k}^{*}, \hat{c}^{*}\right)}=\frac{\frac{(1+\gamma)^{2}}{\beta}+(1-\beta) \cdot a \cdot[(A-\delta-\gamma]-(1-\beta) \cdot a \cdot \gamma] \cdot(A-\delta-\gamma)}{(1+\gamma) \cdot[1+A-\delta-(1+\beta) \cdot a \cdot(A-\delta)]}
\end{aligned}
$$

The evaluation of the signs of the eigenvalues of the Jacobian matrix in (7) does not produce intelligible results; even though we have only four parameters in the system, no meaningful relation is found when using the trace and the determinant to explore stability properties. Thus, a numerical example is developed, letting parameter $a$ vary, while attributing reasonable values to the other parameters. We follow Guo and Lansing (2002) in choosing $\beta=0.962$ and $\delta=0.067$, and we consider $A=0.148$ [this is a value for the technology parameter that allows a $4 \%$ equilibrium growth rate $(\gamma=0.04)$, when $a=0]$.

The chosen parameterization produces the following results (for $-100 \leq a \leq 100$ and letting $\lambda_{1}$ and $\lambda_{2}$ represent the eigenvalues of the Jacobian matrix in (7)):

- $a \in[-100 ;-28.459) \cup(-28.366 ;-27.494) \cup(-13.873 ;-0.25) \cup(27.932 ; 100] \Rightarrow$ Eigenvalues are complex roots;

- $a \in[-28.459 ;-28.366] \cup[-27.494 ;-27.336] \cup[-0.25 ; 0] \cup[26.372 ; 27.932] \Rightarrow$ Eigenvalues are real roots $\left(\left|\lambda_{1}\right|,\left|\lambda_{2}\right|>1\right)$

- $a \in(-27.336 ;-13.873) \cup(0 ; 26.372) \Rightarrow$ Eigenvalues are real roots $\left(\left|\lambda_{1}\right|<1,\left|\lambda_{2}\right|>1\right)$; 
Looking at the values of the eigenvalues, one observes that local indeterminacy does not occur; saddle-path stability can occur for some negative and positive values of $a$ and, as $a$ becomes increasingly higher in absolute value we will have instability with real or complex eigenvalues. We conclude that under reasonable economic conditions (a depreciation rate of $6.7 \%$, an equilibrium discount rate of $3.95 \%$ and an equilibrium growth rate of $4 \%$ ), the only possibility regarding a stable outcome (saddle-path stability) arises for values of $a$ immediately above zero and for a small interval of negative values. Various stability outcomes are possible and these are very sensitive to variations in the parameter value.

In appendix $\mathrm{B}$, we present a table with the trace and the determinant of the Jacobian matrix, alongside with the two eigenvalues, for different values of $a$. According to the table, a strong negative impact of the output gap over the discount rate generates a non-optimal negative growth rate (for $a<-1 /(\beta \cdot(1-\beta))=-27.356)$. The results in the table confirm, for integer values of $a$, the conditions presented above, i.e., that instability and saddle-path stability outcomes alternate as we change the value of the parameter giving the impact of the output gap over the value of the utility discount rate. In the mentioned table, complex eigenvalues are not displayed but they all possess, with exception of the case $a=-28$, positive real parts, given that the trace is above zero; these positive real parts are lower than one for cases $a \leq 36$, and above one otherwise. In the last column, where instability and saddle-path stability arise in an alternate manner, the instability result is confirmed by presenting the value of the square root of $\operatorname{Det}(J)$. This square root corresponds to the modulus of the complex eigenvalues pair. It is well known that if $\sqrt{\operatorname{Det}(J)}<1$, then solutions converge to equilibrium (stability holds) and the equilibrium point is a stable focus; if $\sqrt{\operatorname{Det}(J)}>1$, then solutions will diverge and the equilibrium will be an unstable focus (trajectories will depart from the equilibrium point in a divergent oscillatory way). In the situations presented in the table of appendix $B$, all the cases involving complex roots are cases in which $\sqrt{\operatorname{Det}(J)}>1$, i.e., cases that display local oscillatory divergence.

4. Endogenous Business Cycles

What should we expect to find when assessing the long run behaviour of the endogenous variables under the parameterization selected in the previous section? Since we have not chosen to stay over any eventual saddle-path, no long term stable trajectories are likely to arise; fixed point stability is absent. However, one observes through numerical experimentation that for an interval of values of $a$, invariant cycles appear. The values of $a$ for which such kind of long term motion exists are all negative, meaning that endogenous cycles are compatible with the intuitive idea that less discounting / more patience arises for a higher output gap.

For the selected set of parameter values, figure 1 displays the bifurcation diagram 1 . We regard that a region of cycles exists and that this stops as we leave the instability area and enter into the region of saddle-path stability, according to the local dynamics characterization. Selecting one of the values of $a$ for which the cycles are present ( $a=-75$ ), figures 2 to 4 draw an attractor and the long term time series of both variables. The attractor corresponds to an invariant cycle, i.e., to a result of complete a-periodicity but where regularity features imply talking about quasi-periodicity rather than chaos.

\section{Figures 1 to $4^{* \star \star}$}

In figures 1 to 4 , we have chosen $\hat{k}_{0}=1, \hat{c}_{0}=0.1$ and $\hat{k}^{*}=1$.

The graphical analysis allows to observe that endogenous business cycles arise in the endogenous time preference model when a positive output gap produces a lower discount rate and a negative output gap leads to a higher discount rate, relatively to the reference level $\rho$. In

1 All the figures in the paper (excluding figure 5) are drawn using IDMC software (interactive Dynamical Model Calculator). This is a free software program available at www.dss.uniud.it/nonlinear, and copyright of M. Lines and A. Medio. 
this way, cycles are self-reinforcing: the persistence of business fluctuations is the result of a process where deviations from the effective output relatively to the potential level imply a change in time preference which induces the output to fluctuate; these fluctuations will imply a permanent lack of coincidence between effective and potential output that in turn triggers once again successive shifts in the time preference, and so on. Hence, the steady state equilibrium is never achieved; cycles are perpetuated.

The values of $a$ for which endogenous cycles arise correspond to values implying a negative long term growth, because they are all below the threshold condition $a=-1 /(\beta \cdot(1-\beta))$. Thus, cycles are the straightforward outcome of the absence of complete rationality. Agents are unable to compute a transversality condition and therefore to act optimally, allowing for the possibility of long run negative growth rates. In this case, the cyclical motion displayed in figures 3 and 4 that is presented for stationary variables $\hat{k}_{t}$ and $\hat{c}_{t}$, characterizes a process through which endogenous cycles define the pattern of diminishing stock of capital and consumption levels in time.

\section{Leisure in the Utility Function}

We now develop an extension of the benchmark model of the previous sections. This extension assumes that leisure is an argument of the utility function. The new setting allows to evidence that cyclical motion is compatible with positive growth rates and, consequently, with an integral optimization scenario that makes good use of the transversality condition. The relevant conclusion is that an endogenous rate of time preference where impatience is inversely related to the output gap is capable of generating aggregate fluctuations on output, capital and consumption that are compatible with a full rationality setup.

Consider that the representative agent is endowed with a unit of time, which can be split in working time and leisure time. Thus, generated output will correspond to $y_{t}=A \cdot k_{t} \cdot u_{t}$, with $u_{t}$ the share of the agent's time allocated to the production of goods. The capital accumulation constraint becomes now $k_{t+1}=\left(1+A \cdot u_{t}-\delta\right) \cdot k_{t}-c_{t}, k_{0}$ given.

The agent attributes utility to leisure and, thus, the utility function gains an additional argument. The following functional form is adopted, $U\left(c_{t}, 1-u_{t}\right)=\ln c_{t}+m \cdot \ln \left(1-u_{t}\right)$, with $m>0$. Under this specification, consumption and leisure generate complementary utility: it produces more utility an intermediate level of both consumption and leisure than a great quantity of one and a low availability of the other. Diminishing marginal utility is assumed for both arguments of the utility function.

We set up the Hamiltonian function,

$H\left(k_{t}, c_{t}, q_{t}\right)=U\left(c_{t}, 1-u_{t}\right)+q_{t+1} \cdot\left[\left(A \cdot u_{t}-\delta\right) \cdot k_{t}-c_{t}\right]$

As in section 2, $\quad q_{t} \equiv \beta\left(x_{t-1}\right) \cdot p_{t}, \quad$ with $\quad \beta\left(x_{t}\right)=1 /\left[1+\rho \cdot\left(1+a \cdot x_{t}\right)\right] \quad$ and $\quad x_{t}=\ln k_{t}-\ln k_{t}^{*}$. First order condition (2) continues to hold; condition (3) gives place, in the present context, to

$\left(1+A \cdot u_{t}-\delta\right) \cdot \beta\left(x_{t}\right) \cdot p_{t+1}+\beta_{k} \cdot p_{t+1} \cdot\left[\left(A \cdot u_{t}-\delta\right) \cdot k_{t}-c_{t}\right]=p_{t}$

A new first-order condition is obtained,

$H_{u}=0 \Rightarrow \frac{m}{1-u_{t}}=\beta\left(x_{t}\right) \cdot p_{t+1} \cdot A \cdot k_{t}$

From conditions (2) and (10), we can establish that

$u_{t}=1-\frac{m}{A} \cdot \frac{c_{t}}{k_{t}}$

Because $u_{t} \in(0,1)$, the following constraint applies to this version of the model: $\frac{c_{t}}{k_{t}}<\frac{A}{m}$.

Taking in consideration (2) and (11), we transform motion equation (9) into a difference equation for the consumption variable that is similar to (4) (this equation is derived in appendix C). The 
transversality condition continues to be $\lim _{t \rightarrow+\infty} k_{t} \cdot \beta\left(x_{t-1}\right)^{t} \cdot p_{t}=0$ and, as before, we begin by assuming that a lack of capacity of the representative agent may lead her to overlook such condition, meaning that eventually the economy might begin growing at a negative rate; however, as stated earlier, cyclical patterns of growth only found for negative growth rates in the original scenario without leisure, now arise in situations where the transversality condition is accounted for.

Considering, once again, variables that do not grow in the steady state, $\hat{k}_{t}$ and $\hat{c}_{t}$, one reaches the dynamic system to be subject to analysis; this is composed by equations (12) and (13),

$$
\begin{aligned}
& \hat{k}_{t+1}=\frac{1+A+\delta}{1+\gamma} \cdot \hat{k}_{t}-\frac{1+m}{1+\gamma} \cdot \hat{c}_{t} \\
& \hat{c}_{t+1}=\frac{1}{1+\gamma} \cdot \frac{1+A-\delta-\rho \cdot a \cdot(A-\delta) \cdot \beta\left(\hat{x}_{t+1}\right)}{1 /\left(\beta\left(\hat{x}_{t}\right) \cdot \hat{c}_{t}\right)+\left(m-(1+m) \cdot \rho \cdot a \cdot \beta\left(\hat{x}_{t+1}\right)\right) /\left((1+A-\delta) \cdot \hat{k}_{t}-(1+m) \cdot \hat{c}_{t}\right)}
\end{aligned}
$$

Comparing system (5)-(6) with (12)-(13), we confirm that the first is a particular case of the second, for $m=0$. Therefore, it will be interesting to study the dynamics of the model as one increases the relevance of leisure in the utility function (i.e., as one increases the value of $m$ ). As before, given the complexity of the expressions of the derived difference equations, this is only achievable under a concrete numerical example.

For now, let us characterize generic results concerning the steady state.

Proposition 3. In the endogenous time preference model with leisure in the utility function, the main economic aggregates will grow, in the steady state, at rate

$\gamma=\frac{1+A-\delta-1 / \beta-\frac{m}{1+m} \cdot(A-\delta)}{1 / \beta+(1-\beta) \cdot a-\frac{m}{1+m}}$

Proof: By applying condition $\hat{k}_{t+1}=\hat{k}_{t} \equiv \hat{k}^{*}$ to (12), we find a unique consumption-capital ratio: $\hat{c}^{*} / \hat{k}^{*}=(A-\delta-\gamma) /(1+m)$. The information provided by this ratio may be used when evaluating (13) under the steady state condition $\hat{c}_{t+1}=\hat{c}_{t} \equiv \hat{c}^{*}$; such evaluation, allows to find the growth rate in the proposition

Observe that under $m=0$, we are back on the growth rate of the model where leisure utility is absent. The impact of increasing the relative relevance of leisure in terms of utility will depend on the value of the other parameters. Proposition 4 states an important result.

Proposition 4. The impact of the relative weight of leisure utility over long term growth will depend on the value of the parameter of the discount function:

If $a<-\frac{1+A-\delta}{(A-\delta) \cdot \beta}$, then the potential growth rate increases along with $m$;

If $a>-\frac{1+A-\delta}{(A-\delta) \cdot \beta}$, then the potential growth rate falls with an increase in $m$.

Therefore, as long as the potential growth rate increases with $m$, we assure that patience rises with an increasingly positive (or a decreasingly negative) output gap.

Proof: To prove the proposition we just have to compute the derivative

$$
\frac{\partial \gamma}{\partial m}=\frac{1}{(1+m)^{2}} \cdot \frac{\left(1+A-\delta-1 / \beta-\frac{m}{(1+m)} \cdot(A-\delta)\right)-(A-\delta) \cdot\left(1 / \beta+(1-\beta) \cdot a-\frac{m}{(1+m)}\right)}{\left(1 / \beta+(1-\beta) \cdot a-\frac{m}{1+m}\right)^{2}}
$$


A negative derivative implies that as $m$ increases, $\gamma$ falls, and the opposite for a derivative with a positive sign. The above expression has a negative sign if

$\left(1+A-\delta-1 / \beta-\frac{m}{(1+m)} \cdot(A-\delta)\right)<(A-\delta) \cdot\left(1 / \beta+(1-\beta) \cdot a-\frac{m}{(1+m)}\right)$, which is

equivalent to the second condition in the proposition; if we want to obtain a positive value for the derivative, the symmetric condition applies (this is the first condition in the proposition).

Applying the benchmark parameter values of previous sections, we have

$$
\gamma=\frac{0.042-0.081 \cdot \frac{m}{1+m}}{1.04+0.038 \cdot a-\frac{m}{1+m}} \text {; this value increases with an increase in } m \text { if } a<-13.873 \text {, and it }
$$

decreases with an increase in $m$ if $a>-13.873$.

Concerning steady state results, one can also present the following,

Proposition 5. For an interior steady state solution, the following constraints on the value of $m$ must be satisfied:

i) $m<\frac{\frac{\beta}{1-\beta}+(1-\beta) \cdot a-\frac{1-\beta}{A} \cdot\left[a \cdot(\mathrm{A}-\delta)+\frac{1+A-\delta}{\beta}\right]}{\text {; }}$

$$
\frac{\frac{1}{\beta}+(1-\beta) \cdot a}{-\frac{1-\beta}{A} \cdot\left[a \cdot(\mathrm{A}-\delta)+\frac{1+A-\delta}{\beta}\right]}
$$

ii) $m: \frac{a \cdot(\mathrm{A}-\delta)+(1+A-\delta) / \beta}{(1+m) \cdot\left(\frac{1}{\beta}+(1+\beta) \cdot a\right)-m}>0$.

The second condition can be presented in more detail if one takes two cases,

a) $a<-\frac{1+A-\delta}{(\mathrm{A}-\delta) \cdot \beta} \Rightarrow m<-\frac{1 / \beta+(1-\beta) \cdot a}{(1-\beta) / \beta+(1-\beta) \cdot a}$;

b) $a>-\frac{1+A-\delta}{(\mathrm{A}-\delta) \cdot \beta} \Rightarrow m>-\frac{1 / \beta+(1-\beta) \cdot a}{(1-\beta) / \beta+(1-\beta) \cdot a}$.

Proof: Replacing the steady state growth rate in the steady state consumption-capital ratio, which was presented in the proof of proposition 3 , one obtains an expression for this long term ratio that is a function of our several parameters: $\frac{\hat{c}^{*}}{\hat{k}^{*}}=(1-\beta) \cdot \frac{a \cdot(\mathrm{A}-\delta)+(1+A-\delta) / \beta}{(1+m) \cdot(1 / \beta(1-\beta) \cdot a)-m \text {. }}$.

This ratio has to be a positive value, and this requirement corresponds precisely to the second condition in the proposition. Noticing that $u_{t}$ is given by (11), the steady state value of the share of time allocated to working hours is

$$
u^{*}=1-\frac{m}{\mathrm{~A}}(1-\beta) \cdot \frac{a \cdot(A-\delta)+(1+\mathrm{A}-\delta) / \beta}{(1+m) \cdot(1 / \beta+(1-\beta) \cdot a)-m} \text {. To guarantee an interior solution, the }
$$

value of $u^{*}$ must rest between 0 and $1 ; u^{*}<1$ is guaranteed under the same condition that allows for assuring that the consumption-capital ratio is positive; the condition $u^{*}>0$ implies a value of $m$ bounded by the first constraint in the proposition

Once more, steady state results may be illustrated for the specific numerical case under consideration. Take the chosen parameter values, including $a=-75$. In this case, we have: 
$\gamma=\frac{0.042-0.04 \cdot m}{0.04 m-1.811} ; \quad \frac{\hat{c}^{*}}{\hat{k}^{*}}=\frac{0.184}{1.811+2.811 \cdot m} ; \quad u^{*}=\frac{1.811+1.569 \cdot m}{1.811+2.811 \cdot m}$. Our example obeys the

Our example obeys the constraints that are necessary to impose to parameters. First, note that relatively to the growth rate this is negative for $m=0(\gamma=-0.023)$, as one remarked in the analysis of the benchmark case; note too that as $m$ increases the growth rate also increases, a result that is in accordance with proposition 4. The growth rate becomes positive for $m>1.051$. The chosen parameter values allow for an admissible interior solution, as characterized in proposition 5 , since the consumption-capital ratio is positive and the share $u^{*}$ is clearly bounded between 0 and 1.

Regard that under this example, a higher relative utility of leisure reduces the level of the steady state consumption-capital ratio. A higher relative utility of leisure implies, as well, that the share of work time declines. This second result is, indeed, intuitive, reflecting in this way that our parameters are able to characterize reasonable economic conditions.

To understand the dynamics of the model with leisure, we proceed as with the benchmark framework, first by looking at local dynamics and, on a second stage, by analyzing global dynamic properties.

In terms of local dynamics, we compute the elements of the Jacobian matrix,

$\left.\frac{\partial \hat{k}_{t+1}}{\partial \hat{k}_{t}}\right|_{\left(\hat{k}^{*}, \hat{c}^{*}\right)}=\frac{1+A-\delta}{1+\gamma}$

$\left.\frac{\partial \hat{k}_{t+1}}{\partial \hat{c}_{t}}\right|_{\left(\hat{k}^{*}, \hat{c}^{*}\right)}=-\frac{1+m}{1+\gamma}$

$\left.\frac{\partial \hat{c}_{t+1}}{\partial \hat{k}_{t}}\right|_{\left(\hat{k}^{*}, \hat{c}^{*}\right)}=\frac{A-\delta-\gamma}{(1+\gamma) \cdot[1+A-\delta-(1-\beta) \cdot a \cdot(A-\delta)] \cdot(1+m)} ;$

$\left[(1-\beta)^{2} \cdot a^{2} \cdot(1+\mathrm{A}-\delta) \cdot \gamma-\frac{1-\beta}{\beta} \cdot a \cdot(1+\gamma)^{2}+\left(\frac{m}{1+m}-(1-\beta) \cdot a\right) \cdot(1+A-\delta) \cdot(\mathrm{A}-\delta-\gamma)\right]$

$\left.\frac{\partial \hat{c}_{t+1}}{\partial \hat{c}_{t}}\right|_{\left(\hat{k}^{*}, \hat{c}^{*}\right)}=\frac{1}{(1+\gamma) \cdot[1+A-\delta-(1-\beta) \cdot a \cdot(A-\delta)]}$.

$\left[\frac{(1+\gamma)^{2}}{\beta}+(1-\beta) \cdot a \cdot((A-\delta-\gamma)-(1-\beta) \cdot a \cdot \gamma) \cdot(A-\delta-\gamma)-\frac{m}{1+m} \cdot(A-\delta-\gamma)^{2}\right]$

The previous expressions are not easy to work with; from a generic point of view, one can just confirm that imposing $m=0$, we are back on the non leisure case. To address the present model's local dynamics, we proceed by assuming all the previous parameter values plus a variable $m$; in this way, we can explore how a change in the leisure parameter changes dynamic results. The numerical example allows to reach the following outcome: independently of the value of $m$, the eigenvalues of the Jacobian matrix are always complex values and instability prevails; for $m=0$ the trace and the determinant of the Jacobian matrix are $\operatorname{Tr}(J)=1.872$ and $\operatorname{Det}(J)=1.091$, and these will decrease as one increases the value of $m$, such that $\lim _{t \rightarrow+\infty} \operatorname{Tr}(J)=1.851$ and $\lim _{t \rightarrow+\infty} \operatorname{Det}(J)=1.01$. 
Since the determinant stays always above unity, we confirm the presence of instability, independently of the value of the parameter. This result can be confirmed by looking at the upper left panel of figure 5 . The several panels in this figure represent the relation between the trace (on the horizontal axis) and the determinant (on the vertical axis) of the Jacobian matrix of the system under analysis. This relation is drawn, for each one of the considered values of parameter $a$, for any possible positive value of $m$. One verifies that in most of the circumstances instability will prevail independently of the value of $m$; however, for some values of $a$ (e.g. $a=-10$ or $a=-5$ ) saddle-path stability is found.

\section{Figure 5}

The table in appendix $\mathrm{D}$ presents the values of the trace and determinant for different values of $a$, in the two extremes, $m=0$ and $m \rightarrow+\infty$. The correctness of these values can be checked by looking at the extremes of the lines in the various graphics of figure 5 .

In terms of global dynamics, we already know that, for the considered parameterization (including $a=-75$ ), cycles exist when $m=0$. The graphical representation of a bifurcation diagram, for $m$ as the bifurcation parameter, allows for extending this result. Figure 6 displays the bifurcation diagram and figure 7 presents a long run attractor for a value of $m$ different from 0 . As in the benchmark case, we consider $\hat{k}_{0}=1, \hat{c}_{0}=1$ and $\hat{k}^{*}=1$ to draw the figures.

\section{Figures 6 and 7}

Figure 6 allows for observing that only for values of $m$ from 0 to around 2 to 3 , it is possible to find cycles; afterwards, instability will prevail. We also see that cycles will slightly reduce their amplitude as one increases $m$. The figure refers to a bifurcation diagram, as figure 1, but we are unable to identify any bifurcation point: there is an abrupt jump from cycles to instability; however, the kind of cycles that we obtain are characteristic of the fluctuations produced by a Neimark-Sacker bifurcation (or Hopf bifurcation in discrete time), since such fluctuations correspond to quasi-periodic orbits (see Medio and Lines, 2001, for details on bifurcations and classification of types of cyclical motion). A Neimark-Sacker bifurcation occurs when the determinant of the Jacobian matrix crosses unity, and cycles will arise for values of the determinant above unity; this is compatible with the results found on the numerical investigation.

The attractor in figure 7 reveals one important point that was absent in the original model; in the model without leisure in the utility function, cycles only arose for negative growth rates; now, as we have referred, we have a positive growth rate for $m>1.0506$, and cycles continue to exist for values of $m$ above this level. In the example in figure 6, we have $m=2$, which implies a steady state growth rate around $0.5 \%$, and in this case we observe that quasi-periodic cycles continue to exist. Hence, the particular example contains two relevant ideas for the interval of values of $m$ for which cycles are observed: first, as the relevance of leisure in the utility function increases, cycles decrease their amplitude; second, as the relevance of leisure in the utility function increases, the economy's long term / potential growth rate increases as well.

The second of the above ideas must be re-emphasized as the main result of the analysis. While we have begun by stating that persistent cyclical motion is possible in the standard Ramsey growth model with an endogenous time preference, but only if taking an assumption of lack of rationality that leads agents to be unable to rule out negative growth rates from their decision plans, the introduction of leisure into the precise same setting allows for aggregate fluctuations that are fully compatible with an optimization scenario.

Other cases, concerning other values of $a$ (as the ones in table 1), do not produce significantly different results. In fact, numerical exploration allows to identify only two global dynamics results: instability (i.e., impossibility of finding any long term path for capital and consumption) and quasi-periodic cycles, that are mostly found for significantly negative values of parameter $a$. 


\section{Conclusions}

A discrete time version of the simple AK endogenous growth model was modified by considering endogenous time preference. Intertemporal preference depends on the output gap and the main assumption corresponds to the logical argument that the higher is the effective output relatively to its potential level, the more patient a representative agent tends to be. This modification of the growth model immediately produces complicated dynamics as the relations between variables in the difference equations that characterize the model become nonlinear.

Two versions of the model were developed. The first was the simple Ramsey model of utility maximization, with a constant marginal returns production function. In this version of the model, one can only address the relation between capital and consumption. Instability was dominant (although for some values of the parameter that measures the relation between the output gap and the discount rate, saddle-path stability was observed as well), but below a given negative value of such parameter endogenous business cycles arise. Thus, one concludes that endogenous fluctuations may exist in the simple AK growth model as long as an endogenous intertemporal discount rate is assumed and the relation between the output gap and the discount rate is largely negative. Nevertheless, this endogenous cycles outcome is attained only if a deficiency on optimal behaviour is assumed: negative growth rates arising from neglecting the transversality condition will determine the eventuality of a fluctuations result.

The second version of the model has introduced leisure in the utility function. The scenario in which cycles have arisen in the first model becomes a particular case of a wider framework, where no leisure or a low share of leisure implies cycles, but a relatively high share of leisure leads to global instability. The introduction of leisure allows realizing that a negative growth rate is not essential to observe the presence of cycles, meaning that an endogenous discount rate can effectively generate endogenous fluctuations under a strict optimality scenario. 
Rewrite equation (3) as

$(1+A-\delta)-\rho \cdot a \cdot \beta\left(x_{t}\right) \cdot\left[(A-\delta)-\frac{c_{t}}{k_{t}}\right]=\frac{p_{t}}{\beta\left(x_{t}\right) \cdot p_{t+1}}$

Relation (2) allows replacing the co-state variable by consumption in (A1), as follows,

$(1+A-\delta)-\rho \cdot a \cdot \beta\left(x_{t}\right) \cdot\left[(A-\delta)-\frac{c_{t}}{k_{t}}\right]=\frac{c_{t}}{\beta\left(x_{t-1}\right) \cdot c_{t-1}}$

Equation (A2) is equivalent to

$c_{t}=\frac{(1+A-\delta)-\rho \cdot a \cdot(A-\delta) \beta\left(x_{t}\right)}{1 /\left(\beta\left(x_{t-1}\right) \cdot c_{t-1}\right)-\rho \cdot a \cdot \beta\left(x_{t}\right) / k_{t}}$

Considering (A3) one time period ahead, we have dynamic equation (4).

\section{Appendix B - Local Dynamic Properties for Different Values of $a$ $(a \in\{-50,-49, \ldots, 0, \ldots, 49,50\})$}

\begin{tabular}{ccccccc|c}
\hline$a$ & $\gamma$ & $\operatorname{Tr}(\boldsymbol{J})$ & $\operatorname{Det}(J)$ & $\lambda_{1}$ & $\lambda_{2}$ & Stability result \\
-50 & -0.0482 & 1.9291 & 1.5849 & Complex & Complex & Instability $(\sqrt{\operatorname{Det}(J)}=1.2589)$ \\
\hline-49 & -0.0505 & 1.9319 & 1.5803 & Complex & Complex & Instability $(\sqrt{\operatorname{Det}(J)}=1.2571)$ \\
\hline-48 & -0.0529 & 1.9348 & 1.5766 & Complex & Complex & Instability $(\sqrt{\operatorname{Det}(J)}=1.2556)$ \\
\hline-47 & -0.0556 & 1.9377 & 1.5739 & Complex & Complex & Instability $(\sqrt{\operatorname{Det}(J)}=1.2545)$ \\
\hline-46 & -0.0586 & 1.9408 & 1.5722 & Complex & Complex & Instability $(\sqrt{\operatorname{Det}(J)}=1.2539)$ \\
\hline-45 & -0.0619 & 1.944 & 1.5717 & Complex & Complex & Instability $(\sqrt{\operatorname{Det}(J)}=1.2537)$ \\
\hline-44 & -0.0656 & 1.9474 & 1.5727 & Complex & Complex & Instability $(\sqrt{\operatorname{Det}(J)}=1.2541)$ \\
\hline-43 & -0.0698 & 1.951 & 1.5753 & Complex & Complex & Instability $(\sqrt{\operatorname{Det}(J)}=1.2551)$ \\
\hline-42 & -0.0746 & 1.9549 & 1.5801 & Complex & Complex & Instability $(\sqrt{\operatorname{Det}(J)}=1.257)$ \\
\hline-41 & -0.08 & 1.959 & 1.5875 & Complex & Complex & Instability $(\sqrt{\operatorname{Det}(J)}=1.26)$ \\
\hline-40 & -0.0864 & 1.9636 & 1.5981 & Complex & Complex & Instability $(\sqrt{\operatorname{Det}(J)}=1.2642)$ \\
\hline-39 & -0.0938 & 1.9687 & 1.6129 & Complex & Complex & Instability $(\sqrt{\operatorname{Det}(J)}=1.27)$ \\
\hline-38 & -0.1026 & 1.9745 & 1.6331 & Complex & Complex & Instability $(\sqrt{\operatorname{Det}(J)}=1.2779)$ \\
\hline-37 & -0.1132 & 1.9815 & 1.6609 & Complex & Complex & Instability $(\sqrt{\operatorname{Det}(J)}=1.2887)$ \\
\hline-36 & -0.1263 & 1.9899 & 1.6992 & Complex & Complex & Instability $(\sqrt{\operatorname{Det}(J)}=1.3035)$ \\
\hline-35 & -0.1429 & 2.0008 & 1.7534 & Complex & Complex & Instability $(\sqrt{\operatorname{Det}(J)}=1.3242)$ \\
\hline-34 & -0.1644 & 2.0157 & 1.8327 & Complex & Complex & Instability $(\sqrt{\operatorname{Det}(J)}=1.3538)$ \\
\hline-33 & -0.1935 & 2.0378 & 1.9556 & Complex & Complex & Instability $(\sqrt{\operatorname{Det}(J)}=1.3984)$
\end{tabular}




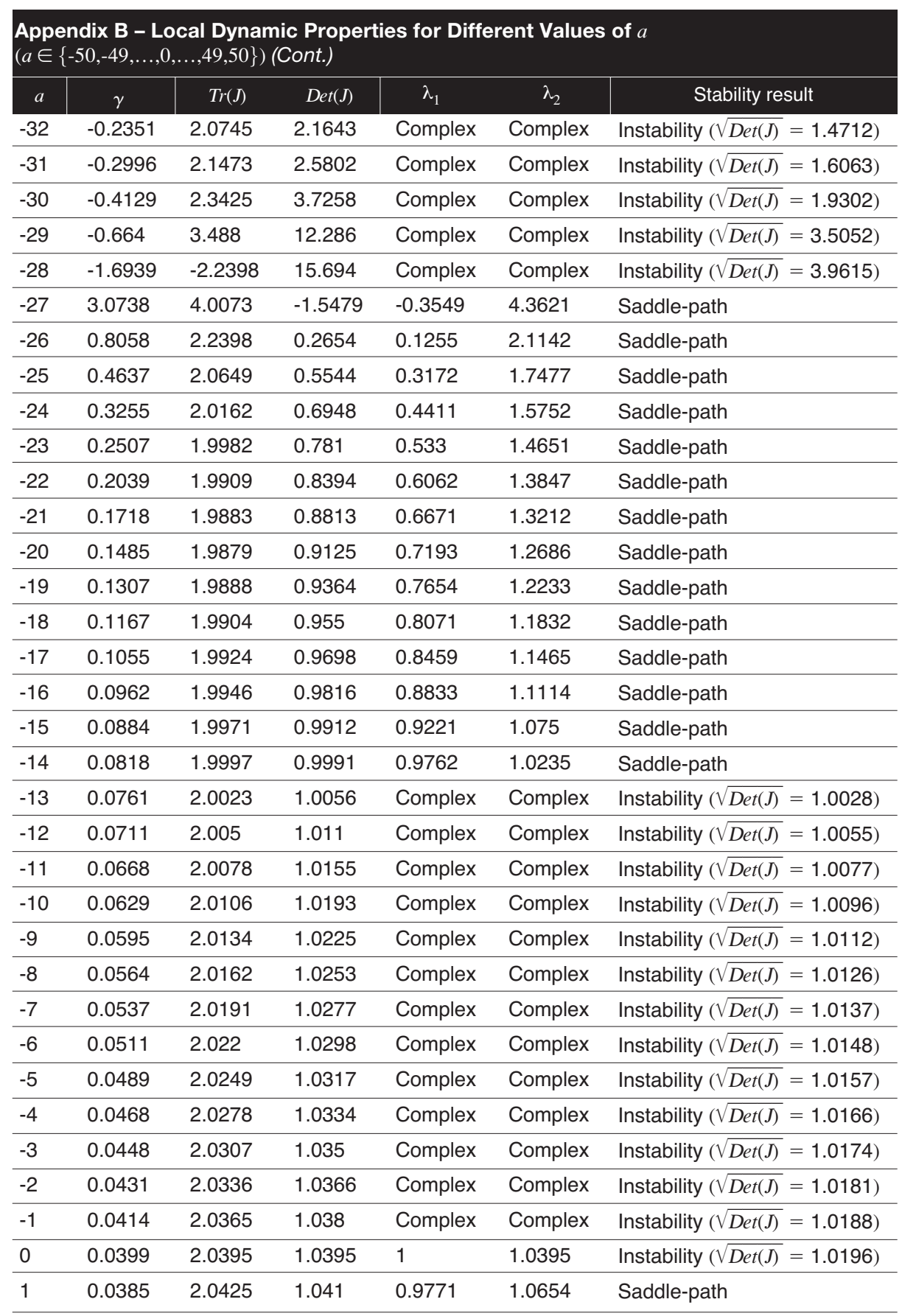




\section{Appendix B - Local Dynamic Properties for Different Values of $a$ \\ $(a \in\{-50,-49, \ldots, 0, \ldots, 49,50\})$ (Cont.)}

$$
\text { a }
$$$$
2
$$$$
3
$$

\begin{tabular}{l|c|cc}
$a$ & $\gamma$ & $\operatorname{Tr}(\boldsymbol{J})$ & $\operatorname{Det}(\boldsymbol{J})$
\end{tabular}

2.0454

1.0425

$\lambda_{1}$

0.9636

$\lambda_{2}$

1.0819

dle-path

4

5

$$
6
$$

$$
\frac{6}{8}
$$

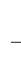

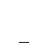$$
10
$$

$$
1
$$

$$
13
$$$$
14
$$

\begin{tabular}{lllllll}
\hline 15 & 0.0258 & 2.0854 & 1.0716 & 0.9177 & 1.1678 & Saddle-path \\
\hline 16 & 0.0252 & 2.0886 & 1.075 & 0.9194 & 1.1692 & Saddle-path \\
\hline 17 & 0.0246 & 2.0918 & 1.0786 & 0.9219 & 1.1699 & Saddle-path \\
\hline 18 & 0.0241 & 2.095 & 1.0823 & 0.9252 & 1.1699 & Saddle-path \\
\hline 19 & 0.0236 & 2.0983 & 1.0863 & 0.9292 & 1.1691 & Saddle-path \\
\hline 20 & 0.0231 & 2.1015 & 1.0905 & 0.9342 & 1.1674 & Saddle-path \\
\hline 21 & 0.0226 & 2.1048 & 1.0949 & 0.9401 & 1.1647 & Saddle-path \\
\hline 22 & 0.0221 & 2.1081 & 1.0996 & 0.9471 & 1.161 & Saddle-path \\
\hline 24 & 0.0217 & 2.1114 & 1.1045 & 0.9555 & 1.1559 & Saddle-path \\
\hline 25 & 0.0213 & 2.1147 & 1.1096 & 0.9655 & 1.1492 & Saddle-path \\
\hline 26 & 0.0209 & 2.1181 & 1.1149 & 0.9777 & 1.1404 & Saddle-path \\
\hline 27 & 0.0201 & 2.1248 & 1.1264 & 1.0143 & 1.1105 & Instability $(\sqrt{\operatorname{Det}(J)}=1.0613)$ \\
\hline 29 & 0.0197 & 2.1282 & 1.1325 & Complex & Complex & Instability $(\sqrt{\operatorname{Det}(J)}=1.0642)$ \\
\hline 30 & 0.0194 & 2.1316 & 1.1389 & Complex & Complex & Instability $(\sqrt{\operatorname{Det}(J)}=1.0672)$ \\
\hline 31 & 0.019 & 2.1351 & 1.1455 & Complex & Complex & Instability $(\sqrt{\operatorname{Det}(J)}=1.0703)$ \\
\hline 32 & 0.0184 & 2.142 & 1.1595 & Complex & Complex & Instability $(\sqrt{\operatorname{Det}(J)}=1.0768)$ \\
\hline 33 & 0.0181 & 2.1455 & 1.167 & Complex & Complex & Instability $(\sqrt{\operatorname{Det}(J)}=1.0803)$ \\
\hline 34 & 0.0178 & 2.149 & 1.1747 & Complex & Complex & Instability $(\sqrt{\operatorname{Det}(J)}=1.0838)$ \\
\hline 35 & 0.0175 & 2.1526 & 1.1827 & Complex & Complex & Instability $(\sqrt{\operatorname{Det}(J)}=1.0875)$ \\
\hline & & & & & & \\
\hline 21.1385 & 1.1524 & Complex & Complex & Instability $\sqrt{\operatorname{Det}(J)}=1.0735)$ \\
\hline 25 & & & & &
\end{tabular}




\begin{tabular}{|c|c|c|c|c|c|c|}
\hline$a$ & $\gamma$ & $\operatorname{Tr}(J)$ & $\operatorname{Det}(J)$ & $\lambda_{1}$ & $\lambda_{2}$ & Stability result \\
\hline 36 & 0.0172 & 2.1561 & 1.191 & Complex & Complex & Instability $(\sqrt{\operatorname{Det}(J)}=1.0913)$ \\
\hline 37 & 0.017 & 2.1597 & 1.1996 & Complex & Complex & Instability $(\sqrt{\operatorname{Det}(J)}=1.0952)$ \\
\hline 38 & 0.0167 & 2.1633 & 1.2084 & Complex & Complex & Instability $(\sqrt{\operatorname{Det}(J)}=1.0993)$ \\
\hline 39 & 0.0165 & 2.167 & 1.2176 & Complex & Complex & Instability $(\sqrt{\operatorname{Det}(J)}=1.1034)$ \\
\hline 40 & 0.0162 & 2.1706 & 1.2271 & Complex & Complex & Instability $(\sqrt{\operatorname{Det}(J)}=1.1077)$ \\
\hline 41 & 0.016 & 2.1743 & 1.2368 & Complex & Complex & Instability $(\sqrt{\operatorname{Det}(J)}=1.1121)$ \\
\hline 42 & 0.0157 & 2.178 & 1.2469 & Complex & Complex & Instability $(\sqrt{\operatorname{Det}(J)}=1.1167)$ \\
\hline 43 & 0.0155 & 2.1817 & 1.2573 & Complex & Complex & Instability $(\sqrt{\operatorname{Det}(J)}=1.1213)$ \\
\hline 44 & 0.0153 & 2.1855 & 1.268 & Complex & Complex & Instability $(\sqrt{\operatorname{Det}(J)}=1.1261)$ \\
\hline 45 & 0.0151 & 2.1892 & 1.2791 & Complex & Complex & Instability $(\sqrt{\operatorname{Det}(J)}=1.131)$ \\
\hline 46 & 0.0149 & 2.193 & 1.2904 & Complex & Complex & Instability $(\sqrt{\operatorname{Det}(J)}=1.136)$ \\
\hline 47 & 0.0147 & 2.1968 & 1.3021 & Complex & Complex & Instability $(\sqrt{\operatorname{Det}(J)}=1.1411)$ \\
\hline 48 & 0.0145 & 2.2007 & 1.3141 & Complex & Complex & Instability $(\sqrt{\operatorname{Det}(J)}=1.1464)$ \\
\hline 49 & 0.0143 & 2.2045 & 1.3265 & Complex & Complex & Instability $(\sqrt{\operatorname{Det}(J)}=1.1517)$ \\
\hline 50 & 0.0141 & 2.2084 & 1.3392 & Complex & Complex & Instability $(\sqrt{\operatorname{Det}(J)}=1.1572)$ \\
\hline
\end{tabular}

\section{Appendix C - Derivation of the Consumption Difference Equation in the Model with Leisure}

Given the expression of the derivative $\beta_{k}$ that one has computed in section 2, we rewrite (9),

$\left(1+A \cdot u_{t}-\delta\right)-\rho \cdot a \cdot \beta\left(x_{t}\right) \cdot\left[\left(A \cdot u_{t}-\delta\right)-\frac{c_{t}}{k_{t}}\right]=\frac{p_{t}}{\beta\left(x_{t}\right) \cdot p_{t+1}}$

Condition (2) holds under optimality, and thus $(C 1)$ is equivalent to

$\left(1+A \cdot u_{t}-\delta\right)-\rho \cdot a \cdot \beta\left(x_{t}\right) \cdot\left[\left(A \cdot u_{t}-\delta\right)-\frac{c_{t}}{k_{t}}\right]=\frac{c_{t}}{\beta\left(x_{t-1}\right) \cdot p_{t-1}}$

Now, we replace $u_{t}$ by the equivalent expression in (11) to obtain

$\left(1+A-\delta-m \cdot \frac{c_{t}}{k_{t}}\right)-\rho \cdot a \cdot \beta\left(x_{t}\right) \cdot\left[A-\delta-(1+m) \cdot \frac{c_{t}}{k_{t}}\right]=\frac{c_{t}}{\beta\left(x_{t-1}\right) \cdot c_{t-1}}$

Solving (C3) in order to $c_{t}$, one will have

$c_{t}=\frac{1+A-\delta-\rho \cdot a \cdot(A-\delta) \cdot \beta\left(x_{t}\right)}{1 /\left(\beta\left(x_{t-1}\right) \cdot c_{t-1}\right)+\left(m-(1+m) \cdot \rho \cdot a \cdot \beta\left(x_{t}\right)\right) / k_{t}}$

Difference equation (C4) is easily transformed in (13) through the consideration of the definitions of $\hat{k}_{t}$ and $\hat{c}_{t}$. 


\section{0 a}

Appendix D - Trace and determinant of the Jacobian matrix of the linearized system for

the model with leisure in the utility function

\begin{tabular}{c|cc|c|c}
\hline$a$ & & $m=0$ & \multicolumn{2}{c}{$m \rightarrow+\infty$} \\
\hline-75 & $\operatorname{Tr}(\boldsymbol{J})$ & $\operatorname{Det}(\boldsymbol{J})$ & $\operatorname{Tr}(\boldsymbol{J})$ & $\operatorname{Det}(\boldsymbol{J})$ \\
\hline-50 & 1.872 & 1.091 & 1.851 & 1.01 \\
\hline-30 & 1.929 & 1.117 & 1.906 & 1.006 \\
\hline-25 & 2.343 & 1.457 & 1.956 & 1.003 \\
\hline-20 & 2.065 & 0.644 & 1.969 & 1.003 \\
\hline-15 & 1.988 & 0.937 & 1.983 & 1.002 \\
\hline-10 & 1.997 & 0.993 & 1.997 & 1 \\
\hline-5 & 2.011 & 1.017 & 2.011 & 0.998 \\
\hline 0 & 2.025 & 1.031 & 2.026 & 0.992 \\
\hline 5 & 2.04 & 1.04 & 2.04 & 1.04 \\
\hline 10 & 2.055 & 1.046 & 2.056 & 1.008 \\
\hline
\end{tabular}




\section{References}

Balasko, Y.; Ghiglino, C. (1995) On the existence of endogenous cycles, Journal of Economic Theory, 67, 566-577.

Becker, G. S.; Mulligan, C. B. (1997) The endogenous determination of time preference, Quarterly Journal of Economics, 107, 729-758.

Boldrin, M.; Nishimura, K.; Shigoka T.; Yano M. (2001) Chaotic equilibrium dynamics in endogenous growth models, Journal of Economic Theory, 96, 97-132.

Caballé, J.; Jarque X.; Michetti, E. (2006) Chaotic dynamics in credit constrained emerging economies, Journal of Economic Dynamics and Control, 30, 1261-1275.

Cellarier, L. (2006) Constant gain learning and business cycles, Journal of Macroeconomics, 28, 51-85.

Christiano, L.; Harrison, S. (1999) Chaos, sunspots and automatic stabilizers, Journal of Monetary Economics, 44, 3-31.

Dolmas, J. (1996) Recursive utility and balanced growth, Journal of Economic Dynamics and Control, 20, 657-680.

Drugeon, J. P. (1996) Impatience and long-run growth, Journal of Economic Dynamics and Control, 20, 281-313.

Drugeon, J. P. (1998) A model with endogenously determined cycles, discounting and growth, Economic Theory, 12, 349-369.

Epstein, L. G. (1987) A simple dynamic general equilibrium model, Journal of Economic Theory, 41, 68-95.

Guo, J. T.; Lansing, K. J. (2002) Fiscal policy, increasing returns and endogenous fluctuations, Macroeconomic Dynamics, 6, 633-664.

Hausman, J. A. (1979) Individual discount rates and the purchase and utilization of energy-using durables, Bell Journal of Economics, 10, 33-54.

Lawrance, E. C. (1991) Poverty and the rate of time preference: evidence from the panel data, Journal of Political Economy, 99, 54-77.

Medio, A.; Lines M. (2001) Nonlinear dynamics: a primer, Cambridge UK, Cambridge University Press.

Meng, Q. (2006) Impatience and equilibrium indeterminacy, Journal of Economic Dynamics and Control, 30, 2671-2692.

Nishimura, K.; Sorger, G.; Yano, M. (1994) Ergodic chaos in optimal growth models with low discount rates, Economic Theory, 4, 705-717.

Nishimura, K.; Yano, M. (1995) "Nonlinear dynamics and chaos in optimal growth: an example, Econometrica, 63, 981-1001.

Palivos, T.; Wang, P.; Zhang, J. (1997) On the existence of balanced growth equilibrium, International Economic Review, 38, 205-224.

Samwick, A. A. (1998) Discount rate homogeneity and social security reform, Journal of Development Economics, 57, 117-146.

Uzawa, H. (1968) Time preference, the consumption function, and the optimum asset holdings, in Wolfe, J. N. (ed.) Value, Capital and Growth: Papers in Honour of Sir John Hicks, Edinburgh, University of Edinburgh Press. 


\section{C5}

\section{Figures}

Figure 1 - Bifurcation diagram $\left(k_{t}, a\right)$

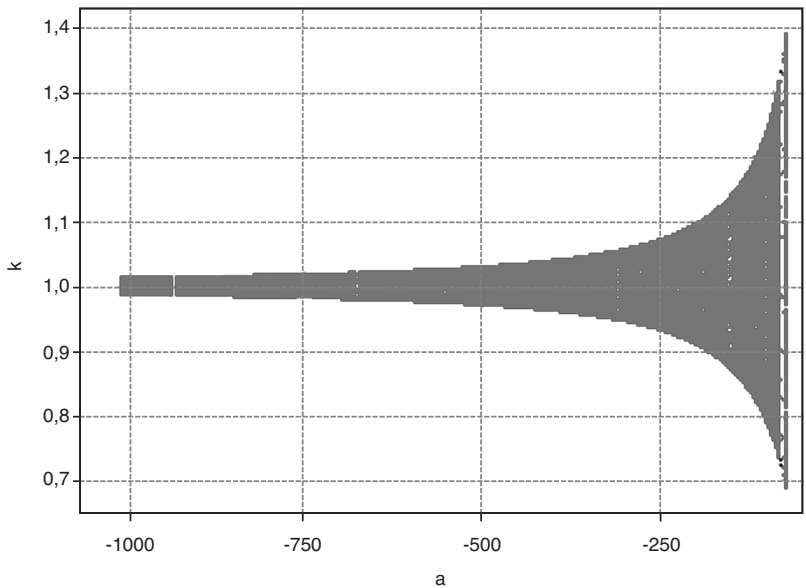

Figure 2 - Attractor $(a=-75)$

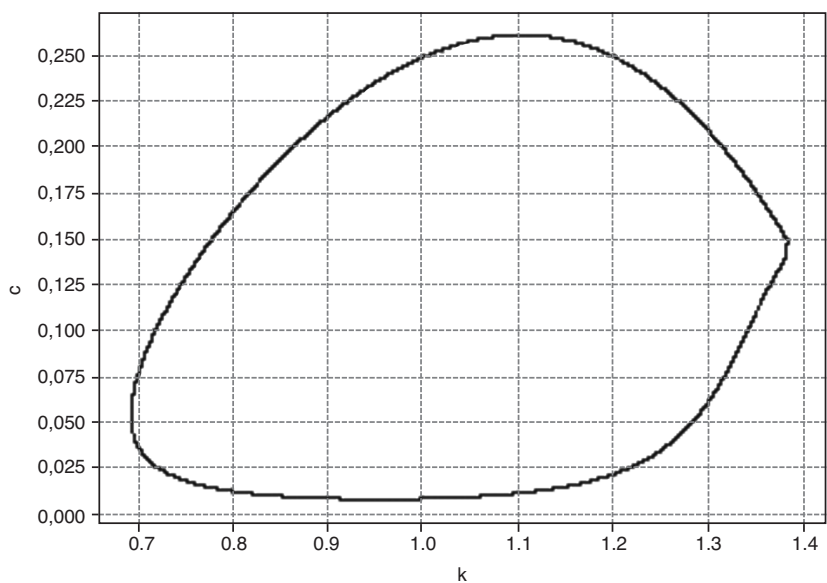




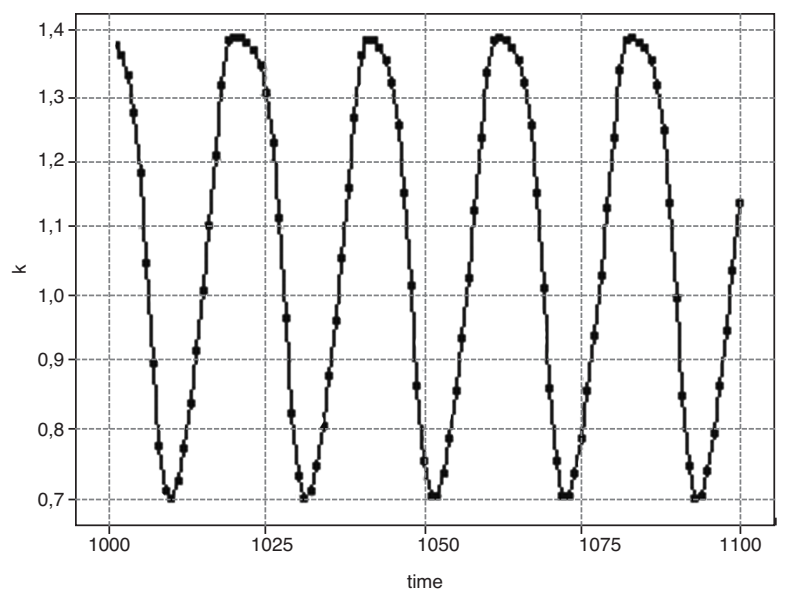

\section{Figure 4 - Long term time series (consumption; $a=-75$ )}

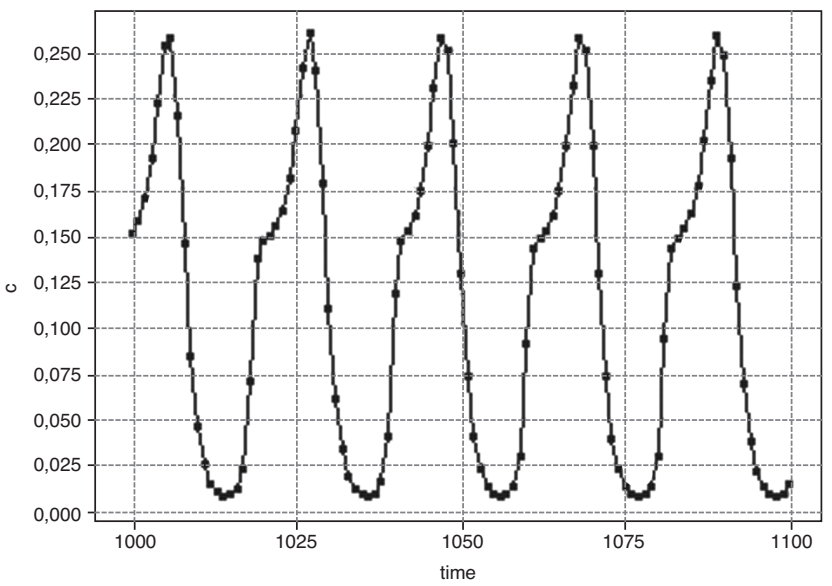




\section{4 55}

Figure 5 - The trace-determinant relation, for $m \geq 0$ and different values of $a$

(the horizontal axis respects to the trace and the vertical axis to the determinant)
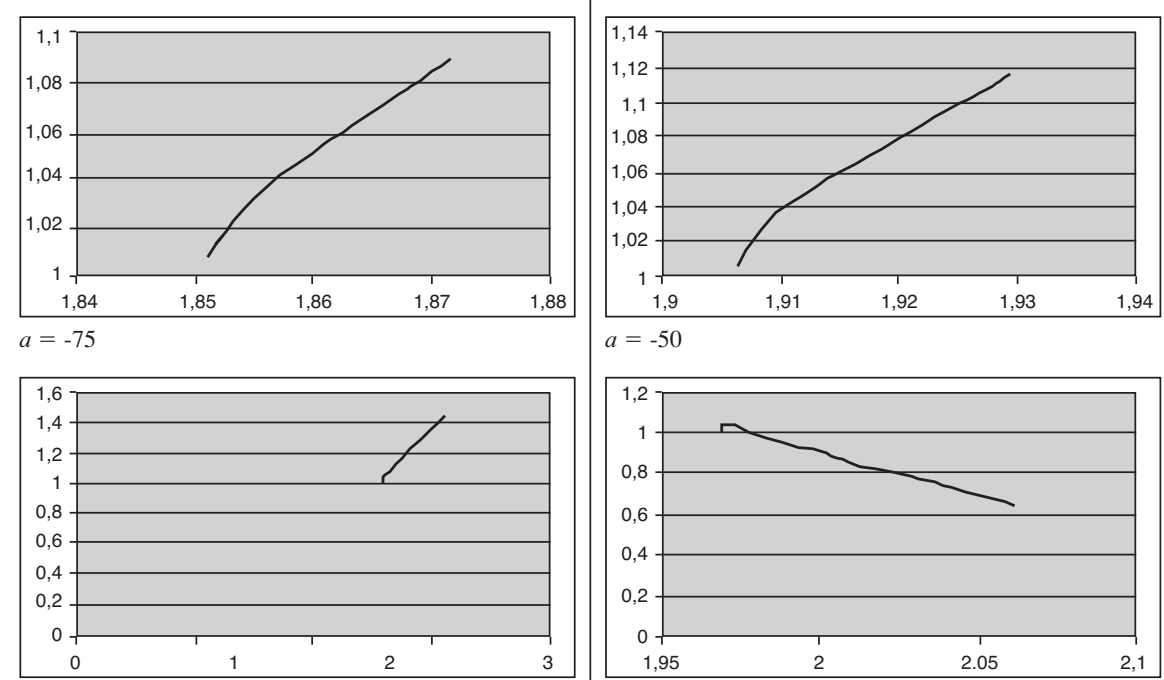

$a=-50$
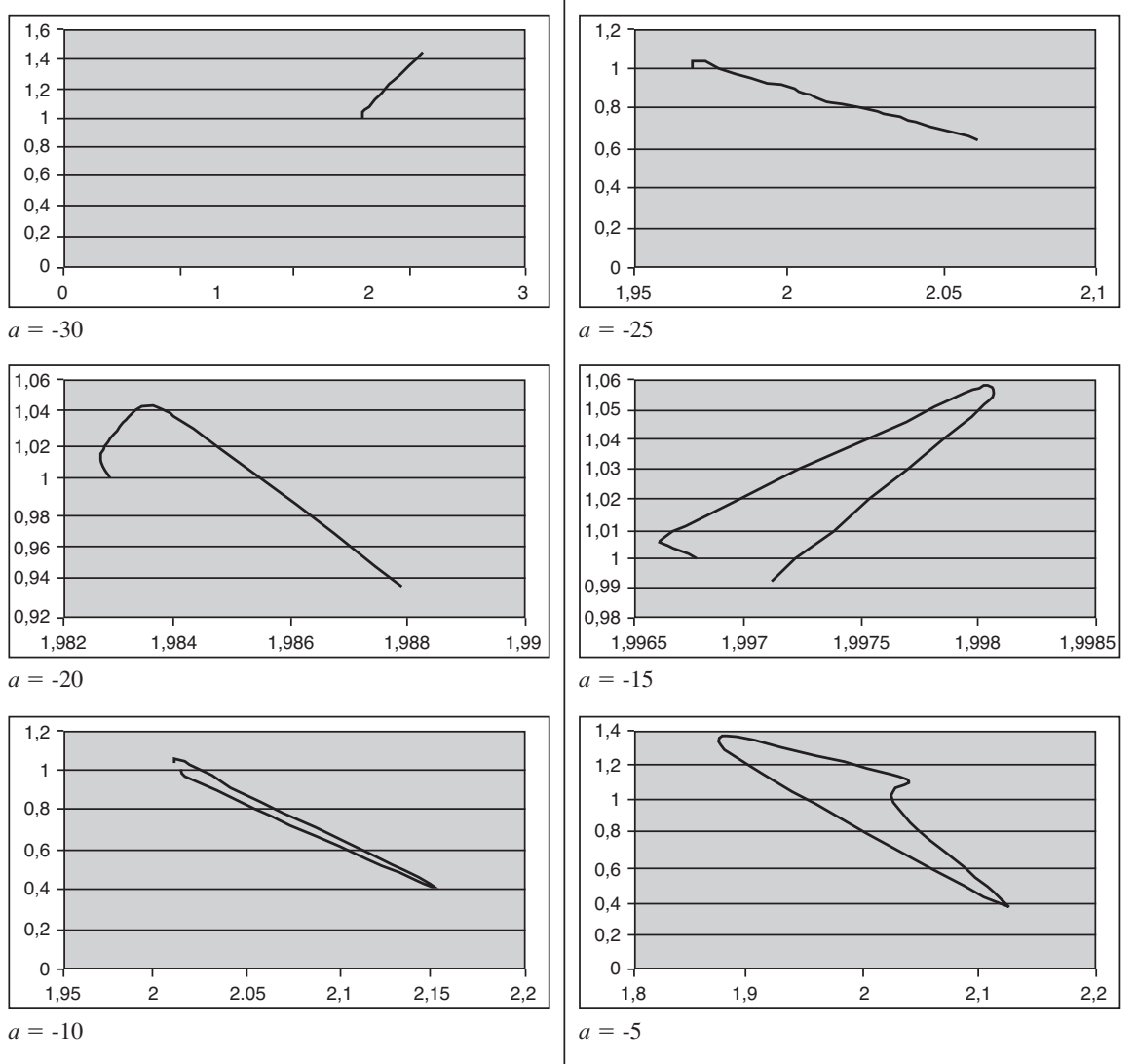


\section{Figure 5 - The trace-determinant relation, for $m \geq 0$ and different values of $a$}

(the horizontal axis respects to the trace and the vertical axis to the determinant) (Cont.)
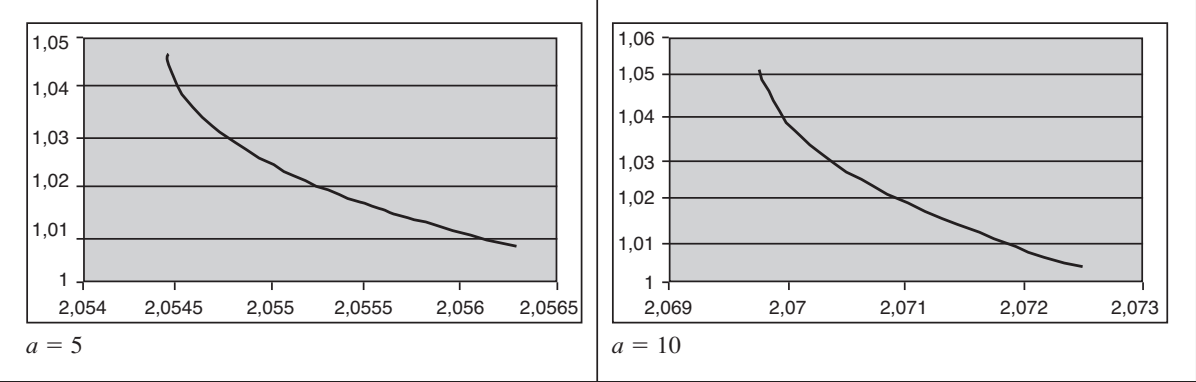

\section{Figure 6 - Bifurcation diagram $\left(k_{t}, m\right)$ (model with leisure in the utility function).}

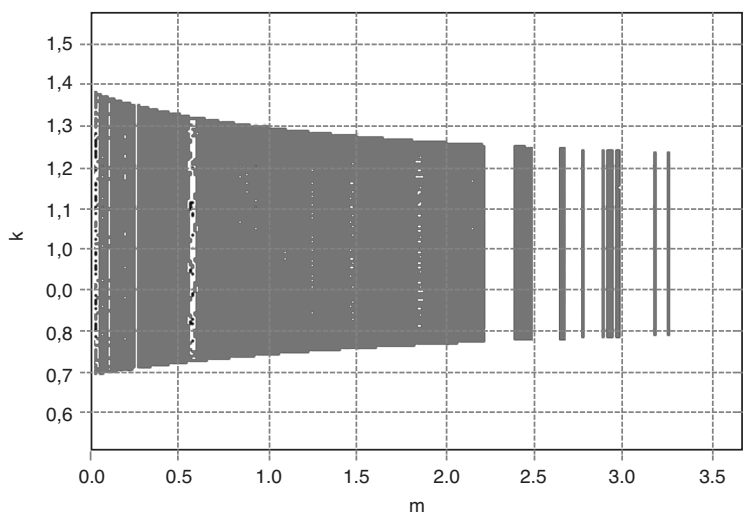

\section{Figure 7 - Attractor (model with leisure in the utility function; $m=2$ ).}

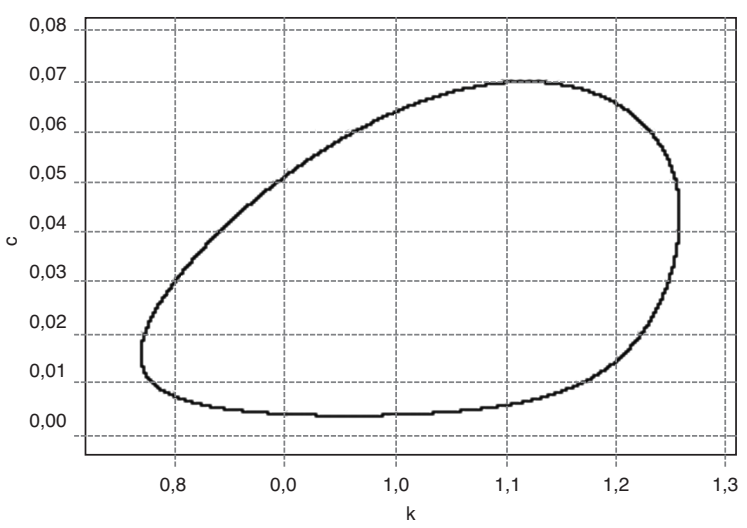

